\title{
Health Systems Approach to Ensure Quality and Safety Amid COVID-19 Pandemic in Pakistan
}

\author{
Nousheen Akber Pradhan ${ }^{1}$, Anam Shahil Feroz ${ }^{1}$ and Syed Mairajuddin Shah ${ }^{2}$ \\ ${ }^{1}$ Department of Community Health Sciences, The Aga Khan University, Karachi, Pakistan \\ ${ }^{2}$ Department of Community Health Sciences \& Family Medicine, The Aga Khan University Hospital, Karachi, Pakistan
}

\begin{abstract}
Ensuring quality and safe care during the coronavirus disease 2019 (COVID-19) pandemic offers a challenge to already strained health systems in low and middle-income countries (LMICs), such as Pakistan with less shock-absorbing capacities. There is a dearth of evidence on mechanisms to provide optimum quality care to COVID-19 patients in the resource-constrained healthcare environment. The lessons learned from the Ebola virus outbreak for the deficient health systems and quality improvement are considered to propose strengthening the health systems response to deliver quality-assured care to patients during the current pandemic. In this regard, the World Health Organization (WHO) health systems framework can serve as a guiding principle towards providing quality-assured and safe healthcare services during the ongoing pandemic in Pakistan by ensuring the availability of an adequate workforce, medical supplies and equipment, strong governance, active information system, and adequate health financing to effectively manage COVID-19. Research evidence is needed to be better prepared for an effective and coordinated health systems response to offer quality and safe care to patients.
\end{abstract}

Key Words: Health systems approach, COVID-19 pandemic, Quality of healthcare, Safe care.

How to cite this article: Pradhan NA, Feroz AS, Shah SM. Health Systems Approach to Ensure Quality and Safety Amid COVID-19 Pandemic in Pakistan. J Coll Physicians Surg Pak 2021; 31(JCPSPCR):CR38-CR41.

COVID-19 pandemic is sweeping across the borders and bringing the death toll to 1,453,355 with over 62 million infected cases (as of $30^{\text {th }}$ Nov 2020). ${ }^{1}$ As evidence keeps evolving with new severe acute respiratory syndrome coronavirus 2 (SARS-CoV-2), people with comorbidities are considered to be at increasingly high risk for contacting COVID-19 with adverse health outcomes. Realities of the poor shock-absorbing capacity of the health systems across the developed and poor nations are getting onto the surface. Since the time pandemic has taken control, scientific evidence keeps flooding in the context of its epidemiology, infectious disease modelling, sub-specialty clinical care, pharmacologic interventions, co-infections with COVID-19, and its clinical management. Furthermore, the psychosocial health effects of the COVID-19 pandemic on frontline healthcare providers are also increasingly getting recognized. The gap remains on evidence related to healthcare system components in offering quality care to patients during the ongoing pandemic. In the wake of the second spell of the COVID-19 pandemic, it is important to investigate what mechanisms are in place to provide good quality and safe care to COVID-19 patients in the resource-constrained healthcareenvironment in low and middle-income countries (LMICs), such as Pakistan.

Correspondence to: Dr. Syed Mairajuddin Shah, Department of Community Health Sciences \& Family Medicine, The Aga Khan University Hospital, Karachi, Pakistan E-mail: mairajuddin.shah@gmail.com

Received: August 18, 2020; Revised: December 01, 2020; Accepted: December 21, 2020

DOI: https://doi.org/10.29271/jcpsp.2021.JCPSPCR.CR38
By now, the first half of 2020 must have given adequate time to countries' health systems from struggling to manage the outbreak to realizing the lessons learned on way towards strengthening their resilience to cope more strongly with this novel coronavirus. This article has concisely reflected on the existing landscape of the healthcare system in Pakistan to recommend key health systems indicators to deliver safe and quality-assured care in context of the COVID-19 pandemic.

Like other countries across the globe, the second wave of COVID-19 has also hit Pakistan, a country that abysmally spends a low amount on health $\left(2.89 \%\right.$ of GDP). ${ }^{2}$ Total cases in the country have reached 398,024 ; of which, $86 \%(341,423)$ cases have recovered. ${ }^{3}$ The death toll stands at 8,025 (as of $30^{\text {th }}$ Nov 2020). ${ }^{3}$ With an increased positivity rate of $6.9 \%,{ }^{3}$ hospitals are again getting overwhelmed with the treatment and management of COVID-19 patients. The pandemic has increased demands for the health workforce worldwide and thus calls for identifying the gaps in workforce shortages, especially among the frontline workers in Pakistan, as the country remains under the severe health workforce crises list. ${ }^{4}$ In Pakistan, the density for health workers (doctors, nurses, and midwives) is 1.45 (for 2017) ${ }_{i}^{5}$ not meeting the minimum required health worker density (SDG threshold index) by WHO for 4.45 doctors, nurses, and midwives per 1,000 population. ${ }^{6}$ Also, the demands for critical care continue to grow as the country is trying to cope with the surge in COVID-19 cases.

Table I: Proposed health systems framework to ensure quality and safe care to COVID-19 patients.

\begin{tabular}{|l|l|}
\hline Building blocks & Indicators \\
\hline
\end{tabular}




\begin{tabular}{|c|c|}
\hline Health workforce & $\begin{array}{l}\text { Health workers (medical, paramedical, and allied health professionals) following adequate hand hygiene } \\
\text { Health workers receiving training and refreshers on COVID-19 standard care protocols } \\
\text { Health workers using appropriate personal protective equipment (PPEs) while managing sick and critically ill } \\
\text { patients } \\
\text { Health workers skilled in diagnosing and case management } \\
\text { Health workers counseling patients and attendants at the time of discharge } \\
\text { Health workers diagnosed with COVID-19 } \\
\text { Case fatality rate among health workers with COVID-19 } \\
\text { Health workers able to access counseling and psychotherapy. } \\
\text { Nurse- to- patient ratio } \\
\text { Nurse- to- bed ratio } \\
\text { Nurse- to- doctor ratio }\end{array}$ \\
\hline Service delivery & $\begin{array}{l}\text { Public and private healthcare facilities following standard treatment of care for COVID-19 patients } \\
\text { Triage protocols developed for screening patients with COVID-19 } \\
\text { Facilities with designated COVID-19 wards } \\
\text { Standards of care followed at quarantine and isolation facilities } \\
\text { Safe sites available for screening and testing services } \\
\text { Alternative arrangements available to continue with routine service delivery } \\
\text { Availability of telemedicine services } \\
\text { Bed capacity in hospitals } \\
\text { Availability of negative pressure rooms for patients } \\
\text { Contact tracing at regular intervals at the community level } \\
\text { Hot spots identified and sealed at district/ city level } \\
\text { Behavior change communication campaigns/activities planned and implemented }\end{array}$ \\
\hline Information system & $\begin{array}{l}\text { Mechanisms in place for/to: } \\
\text { Risk communication } \\
\text { Active and passive surveillance at the facility and outreach } \\
\text { The communication system in place for following protocols for contact with COVID-19 patients and dead } \\
\text { bodies } \\
\text { Dissemination of information on social media and other platforms } \\
\text { Control the spread of false information } \\
\text { Information, education, and communication material available for patients and family education } \\
\text { Monitor employees' health } \\
\text { Providing feedback on DHIS reports } \\
\text { Adequate tools for reporting } \\
\text { Staff training in handling DHIS data }\end{array}$ \\
\hline $\begin{array}{l}\text { Medical supplies and } \\
\text { equipment }\end{array}$ & $\begin{array}{l}\text { The number of facilities with availability of : } \\
\text { Test kits } \\
\text { Oxygen cylinders and other oxygen supplies } \\
\text { Beds } \\
\text { Medications } \\
\text { Ventilators } \\
\text { Incinerators } \\
\text { Appropriate supply of PPEs (gloves, gowns, masks, and face shields) }\end{array}$ \\
\hline Governance & $\begin{array}{l}\text { Procedures in place to ensure: } \\
\text { Strict hand hygiene } \\
\text { Compliance with PPEs usage } \\
\text { Institutionalization of all infection control protocols } \\
\text { Coordination mechanism among multi-disciplinary teams for patient care management } \\
\text { Workplace safety at health care organizations }\end{array}$ \\
\hline Financing & $\begin{array}{l}\text { Funds earmarked to manage public health crises } \\
\text { Funds earmarked for monitoring and evaluation }\end{array}$ \\
\hline
\end{tabular}

With no global benchmark for the number of hospital beds in relation to population, ${ }^{7}$ the functional critical bed capacity in Pakistan is 0.71 per 100,000 population, lesser than the neighboring countries. ${ }^{8}$ Findings from the nationwide survey, held during 2017-2018 in 157 intensive care units (ICUs) across the country, revealed that $54 \%$ of the ICUs had a one-to-one nurse-to-bed ratio for ventilated patients. ${ }^{8}$ Concerning the availability of one-to-one nurse-to-bed ratio, this ranged from $56.5 \%$ having a $1: 1$ availability in Punjab, compared to $0 \%$ in Azad Jammu and Kashmir. Ventilator-to-bed ratio of 1:1 was observed in $52 \%$ of the ICUs, with variations reported across the provinces. ${ }^{8}$ Furthermore, gaps in the critical care trained staff have also been reported. ${ }^{8}$ In context of the current pandemic, there is a need to identify workforce gaps with training needs and infrastructure for critical care across all hospitals in Pakistan to adequately manage COVID-19 patients.

Reliable and timely information is an essential foundation of the healthcare system. In Pakistan, health information gets assembled at the district level from primary, secondary health facilities, outreach services, and vertical programs. Performance of the district health information systems (DHIS) is often reported to be hampered by the inadequate feedback on reports, low utilization of DHIS reports in planning, insufficient availability of DHIS tools, and gaps in the 
training of staff handling DHIS. ${ }^{9}$

While tackling the pandemic, it is appreciable to note that COVID-19 dashboards are created at the national and provincial health departments to provide timely information. With current challenges in the healthcare system in Pakistan, there is all-time low satisfaction reported among patients with the use of public sector health facilities. ${ }^{10,11}$

Epidemics and pandemics weaken the health systems' capacity at large, especially in resource-constrained countries such as Pakistan with low investment in the health sector. The lessons learned from the Ebola virus (EVD) outbreak for the deficient health systems and quality improvement measures must be considered to strengthen the health systems towards delivering quality-assured care to needy patients during the current pandemic in Pakistan. Quality improvement (QI) in health is the "pursuit of continuous performance improvement". ${ }^{12}$ The notion of quality care becomes paramount in context of the exhausted health systems in times of such global health crises. The expectations by patients and family members are presumed to be higher during crises situation, as they see healthcare professionals, the available services, supplies, and other protocols of standard care to improve well-being and save lives. The human, material, financial, and logistics deficiencies surfaced with EVD remain the same to date as identified with the COVID-19 pandemic. ${ }^{13}$ Undoubtedly, ensuring quality and safe care during this ongoing pandemic offers a great challenge to already strained health systems in Pakistan, with less shock-absorbing capacities.

Dealing with an outbreak primarily requires skills in virology, serology, intensive care, and other related disciplines. It also demands a whole systems approach towards virus containment efforts and providing quality care to infected patients. Although, countries have stepped up to re-organize the processes and improve the standards of care amid COVID-19, ${ }^{14}$ yet little evidence is available on how new processes and standards have contributed to the quality of care. Given the surge of COVID-19 in Pakistan, we propose the WHO health systems framework to be used by planners and hospital managers while keeping quality measures at the centre of their activities (Table I). This framework has been adapted from the quality improvement framework proposed for EVD outbreak to strengthen health systems response to deliver quality care. ${ }^{13}$ The proposed health systems framework (Table I) can serve as a guiding principle to ensure quality and safe care to COVID-19 patients not just in Pakistan, but across LMICs, where issues with quality and safety of care are most commonly documented. ${ }^{15}$ The framework presents key indicators across the health systems building blocks on areas addressed in the earlier section and beyond, to manage the COVID-19 pandemic in Pakistan. Loopholes in any of those building blocks may lead to poor quality and unsafe care.
In conclusion, achieving a better understanding of the indicators while using the WHO health systems approach will facilitate planners and managers to be prepared and overcome barriers in providing care to patients. Once the information on the proposed indicators is collected, it will help in navigating how to strengthen health systems response in fighting the COVID-19 pandemic in Pakistan. This uncertain time demands adequate planning, strong governance, adequate human, financial and material resources, standard service delivery measures, and up-to-date information systems in virus containment efforts. While efforts are on way to cope with the global health emergency in Pakistan, we need robust research evidence to be better prepared for an effective and coordinated health systems response to offer quality and safe care to the patients.

\section{CONFLICT OF INTEREST:}

The authors declared no conflict of interest.

\section{AUTHORS' CONTRIBUTION:}

NAP: Conception of the idea and drafting of the manuscript. ASF and SMS: Technical input in the manuscript and review.

\section{REFERENCES}

1. World Health Organization. COVID-19 dashboard. http://covid19.who.int/. (Accessed on 11/30/2020)

2. World Health Organization. Global health expenditure data base. Current health expenditure (\% of GDP) - Pakistan database.http://data.worldbank.org/indicator/SH.XPD.CHEX.GD.ZS?locations=PK. (Accessed on 11/30/2020)

3. Government of Pakistan. Covid-19 situation. http:// covid.gov.pk/. Accessed on (11/30/2020)

4. World Health Organisation. Global health workforce alliance. List of 57 countries facing human resources for health crisis. http://www.who.int/workforcealliance/ countries/57crisiscountries.pdf?ua=1. (Accessed on 11/27/2020)

5. Ministry of National Health Services, Regulations $\&$ Coordination. Pakistan Human Resources for Health Vision. HRH 2018-2030.

6. World Health Organisation. 2016. Health workforce requirements for universal health coverage and the sustainable development goals. Background paper no. 1 to the global strategy on human resources for health.

7. World Health Organization. Health workforce, infrastructure, essential medicines. 2009.

8. Hashmi M, Taqi A, Memon MI, Ali SM, Khaskheli S, Sheharyar $M$, et al. A national survey of critical care services in hospitals accredited for training in a lowermiddle income country: Pakistan. J Crit Care 2020; 60: 273-278. doi: 10.1016/j.jcrc.2020.08.017.

9. Policy brief. Maternal health innovations fundrapid appraisal of Pakistan's district health information system finds encouraging results as well as room for improvement. ICDDR,B, maternal health task foce and Aga Khan University, Pakistan.

10. Naseer M, Zahidie A, Shaikh BT. Determinants of patient's satisfaction with healthcare system in Pakistan: A critical 
review. Pakistan J Public Health 2012; 2(2):52.

11. Hussain M, Khan MS, Wasim A, Sabih S, Saleem S, Mushtaq A. Inpatient satisfaction at tertiary care public hospitals of a metropolitan city of Pakistan. J Pak Med Assoc 2014; 64(12):1392-1397.

12. Leatherman S, Ferris TG, Berwick D, Omaswa F, Crisp N. The role of quality improvement in strengthening health systems in developing countries. Int J Quality Health Care 2010; 22(4):237-243.

13. Brugnara L, Pervilhac $C$, Kohler F, Dramé $M L$, Sax S, Marx M. Quality improvement of health systems in an epidemic context: A framework based on lessons from the Ebola virus disease outbreak in West Africa. Int J Health Planning Management 2020; 35(1):52-67. doi: 10.1002/hpm.2814.

14. Oesterreich S, Cywinski J, Elo B, Geube M, Mathur P. Quality improvement during the COVID-19 pandemic. Cleveland Clinic J Med 2020; doi: 10.3949/ccjm.87a. ccc041.

15. Chou VB, Walker N, Kanyangarara M. Estimating the global impact of poor quality of care on maternal and neonatal outcomes in 81 low-and middle-income countries: A modeling study. PLoS Med 2019; 16(12):e1002990. doi: 10.1371/journal.pmed.1002990. 